\title{
Asumiendo las consecuencias negativas de la adicción al juego
}

\author{
Dealing with the negative consequences of gambling addiction \\ Pilar Blanco Miguel \\ Universidad de Huelva, España \\ pblanco@uhu.es
}

Recibido: 15/04/2015

Revisado: 06/05/2015

Aceptado: 20/01/2016

Disponible on line: 01/07/2016

\section{Resumen}

La adicción al juego no sólo se caracteriza por la pérdida de control ante el juego, sino que esta conducta tiende a generar problemas en los diferentes ámbitos de la vida del ludópata. Por ello, este aspecto se recoge en el Manual diagnóstico y estadístico de los trastornos mentales-5 (DSM-V) como uno de los criterios para realizar su valoración diagnóstica. Objetivo: describir y analizar los diferentes elementos que conforman la compleja problemática aparejada a esta adicción y que pueden terminar en situaciones de exclusión social. Método: Se opta por una metodología cualitativa que se ajusta mejor a los intereses del estudio. Como técnica se ha seleccionado la historia de vida, instrumento de evaluación que permite conocer la verdadera magnitud del problema desde el punto de vista de los afectados. Resultados. De manera general, se ha descubierto que ser ludópata tiene muchos más consecuentes que el problema económico evidente. No debemos despreciar las implicaciones de esta conducta a otros niveles: familiar, laboral, legal y social, que pueden considerarse, a medio plazo, como factores mucho más execrables que el del mero gasto económico. Conclusión. Es fácil avistar que los graves problemas que acarrea la adicción al juego son capaces de desmembrar el proyecto vital del ludópata y el de su familia. Todo vale, aunque para ello tenga que jugarse su puesto de trabajo, su casa, su familia, sus amistades, su estatus social y su propia dignidad.

Palabras clave: adicción al juego, problemática social, consecuencias de la adicción, exclusión social, metodología cualitativa.

\begin{abstract}
Gambling addiction is characterized both by loss of control with respect to gambling and such behaviour leading to problems in the different areas of the addict's life. This is therefore included in the Diagnostic and Statistical Manual of Mental Disorders, Fifth Edition (DSM-V) as one of the criteria for a diagnostic assessment. Aim: to describe and analyse the different elements comprising the complex problems accompanying this addiction that may result in social exclusion. Method: a qualitative methodology was selected, as the best fit for the interests of the study. The life history technique was chosen, as an assessment instrument enabling an understanding of the true magnitude of the problem from the perspective of the persons affected. Results: in general, it was discovered that addiction has many consequences beyond the obvious financial issues. We cannot ignore the implications of this behaviour on other levels: family, work, legal and social, which may in the medium term be considered far more serious factors than mere financial loss. Conclusion: it is easy to recognize that the serious problems caused by gambling addiction are capable of destroying the lives of the addict and of their family. Anything goes, though they may have to risk their job, home, family, friendships, social status and dignity.
\end{abstract}

Keywords: gambling addiction, social issues, consequences of addiction, social exclusion, qualitative methodology.

Referencia normalizada: Blanco Miguel, P. (2016): «Asumiendo las consecuencias negativas de la adicción al juego». Cuadernos de Trabajo Social, 29(2): 335-344.

Sumario: Introducción. 1. Metodología. 2. Resultados. 3. Discusión y conclusiones. 4. Referencias bibliográficas.

\section{Introducción}

Desde que se legalizó el juego en España (1977) el número de jugadores ha ido incrementándose parejo a la inversión realizada en la industria del juego. Aunque, en los últimos años se ha produ- cido un leve descenso de los ingresos obtenidos por el juego (avivado por la crisis económica), las cifras económicas siguen denotando la importancia que tiene este sector en la economía de nuestro país, y más aún hoy, con la incorpora- 
ción en 2011 del juego on line. Pero bajo esta bonanza se esconde una angosta realidad: la realidad del adicto que, sabiéndose perdedor, es capaz de esquilmar su proyecto de vida por unos momentos de juego (Castilla, Berdullas, Vicente y Villamaría, 2013).

Esta realidad nos muestra que el juego forma parte de nuestra vida cotidiana, teniendo que aprender a vivir con él, pero sin dejarnos arrastrar por su perniciosa complacencia. Ya casi nadie duda de que la adición al juego se ha constituido como uno de los problemas más graves a los que se ha de hacer frente y, en este aspecto, España ocupa un lugar privilegiado no sólo en gasto, sino también en problemas o dificultades derivadas de su uso patológico. Aunque las adicciones sociales se revelan como un gran coste económico, en muchos países ya están considerándose como verdaderos problemas de salud pública, a los que los Estados deben dar una respuesta (Salas, 2014).

En parte, todos somos conscientes de que no paran de crecer las cifras de personas que terminan por volverse adictas al juego y así lo atestiguan los últimos estudios que se están llevando a cabo, sobre todo entre la población más joven (Volverg, Gupta, Griffiths, Olason y Delfabbro, 2011). Si antes el perfil medio del ludópata era: varón, entre 30 y 40 años; actualmente se aproxima más a: joven, entre 15 y 35 años, en su mayoría estudiante o con estudios universitarios que cada vez dedican más tiempo a jugar, aunque ello vaya en detrimento de sus estudios, familias y amigos (Castilla, Berdullas, Vicente y Villamaría, 2013). Hecho que la mayoría de los expertos atribuye al gran desarrollo del juego legalizado, cuya extensión - según expresan algunos autores (Salas, 2014; Sarabia, Estévez y Herrero, 2014) — ha sido potenciada por la laxitud de las restricciones legales y la excesiva generosidad o ambigüedad de la legislación reguladora del juego; y en este sentido nuestro país es un claro ejemplo de ello.

Se sabe que la accesibilidad al juego correlaciona positivamente con la probabilidad de practicarlo (Sarabia, Estévez y Herrero, 2014; Olason, Krisjansdottir, Einarsdottir, Haraldsson, Bjarnason y Derevensky, 2011). Actualmente, jugar se plantea como una tarea muy fácil por dos motivos: por la gran oferta de juegos de azar a disposición (King, Delfabbro y Griffiths, 2010) y por la excesiva aceptación social que to- davía sigue teniendo (Blanco, 2014). En contraposición a las drogas, el juego cuenta con el beneplácito de todos, justificándolo a través de una serie de creencias positivas que básicamente pueden resumirse en «su nula peligrosidad y sus cuantiosos beneficios económicos». Esta permisividad allana mucho el camino a los dispendios que se originan en torno al juego; pero los abrumadores datos adversos de carácter humano, social y económico que se agolpan en torno al juego hablan por sí solos; invalidan cualquier opción argumentativa (idem).

\section{Metodología}

Dado que nuestro interés está centrado en analizar y comprender un problema, teniendo como referencia básica a las personas que lo padecen, consideramos necesario elegir una perspectiva metodológica que se sirva de estrategias que permitan comprender el fenómeno que se estudia teniendo en cuenta la dimensión intersubjetiva. Por ello, elegimos la vertiente comprensivo-interpretativa, ya que está interesada -al igual que nosotros - en interpretar y comprender los fenómenos sociales desde el punto de vista de los sujetos que viven el hecho de primera mano; o que, como muy bien apunta Ferrarotti (2006), nos interesa definir los problemas con las palabras de los actores.

De todas ellas, elegimos la historia de vida, ya que — como señala Becker (1974) - tiene una gran capacidad para captar los procesos sociales básicos de la interacción cotidiana. De igual modo, Rojo (1997), apunta que esta técnica ofrece la posibilidad de llegar a comprender las distintas etapas y periodos en la existencia de un individuo en su proceso de desarrollo, poniendo dichas fases en conexión con el momento histórico y con su propia sociedad. Esta técnica se llevó a cabo tanto con las personas enfermas como con sus familiares. En cuanto al ámbito de estudio, se reseña que se seleccionó a la población afectada por la problemática de la ludopatía (jugador y familia) que está en proceso de rehabilitación.

Para ello se ha elegido a la Asociación Onubense de Jugadores en Rehabilitación (AONUJER), situada en Huelva capital, aunque su radio de acción está abierto a toda la provincia. Tras conocer el perfil de los usuarios jugadores, optamos por seguir unos criterios de selección que tuvieran en cuenta variables tan significativas 


\begin{tabular}{|c|c|c|c|c|c|c|c|c|}
\hline \multicolumn{9}{|c|}{ Historias de vida (jugadores/as) } \\
\hline \multirow{2}{*}{ Número } & \multirow{2}{*}{ Sexo } & \multirow{2}{*}{$\begin{array}{c}\text { Intervalo } \\
\text { de edad }\end{array}$} & \multicolumn{2}{|c|}{ Procedencia } & \multicolumn{4}{|c|}{ Nivel de terapia* } \\
\hline & & & Huelva & Provincia & Ma. & Reh. & In. & TP. \\
\hline 18 & Varones & $22-66$ & 5 & 13 & 7 & 4 & 6 & 1 \\
\hline 4 & Mujeres & $39-63$ & 2 & 2 & 2 & 一 & - & 2 \\
\hline \multicolumn{9}{|c|}{ Historias de Vida - Familiares (pareja/cónyuge/hijos) } \\
\hline \multirow{2}{*}{ Número } & \multirow{2}{*}{ Sexo } & \multirow{2}{*}{$\begin{array}{l}\text { Intervalo } \\
\text { de edad }\end{array}$} & \multicolumn{2}{|c|}{ Procedencia } & \multicolumn{4}{|c|}{ Nivel de terapia } \\
\hline & & & Huelva & Provincia & Ma. & Reh. & In. & TP. \\
\hline 3 & Varones & $57-68$ & 2 & 1 & 2 & - & - & 1 \\
\hline 14 & Mujeres & $20-62$ & 5 & 9 & 6 & 3 & 3 & 2 \\
\hline
\end{tabular}

Tabla 1. Perfil de la muestra.

* Concretamente los niveles de terapia son: Mantenimiento (Ma.), Rehabilitación (Reh.) Inicio (In.) y Terapia de pareja (TP.).

Fuente: Elaboración propia.

como el sexo ${ }^{1}$, la edad, la procedencia geográfica, y el nivel de tratamiento en el que se encontraban en ese momento. Para el criterio de elección de los familiares se creyó conveniente elegir al familiar del jugador que previamente hubiera sido seleccionado en la muestra del colectivo de jugadores.

\section{Resultados}

Nuestros entrevistados y entrevistadas saben mejor que nadie que la adición al juego no viene caracterizada sólo por la pérdida del control ante el juego, sino que deviene una conducta capaz de generar problemas muy serios, que pueden afectar a toda su vida. Además de la evidencia explícita del problema económico, la adicción al juego conlleva situaciones muy difíciles a nivel personal, laboral, social y legal que, a su vez, tiene un impacto muy nocivo en el ámbito familiar.

\subsection{Derivaciones personales}

Si en un principio jugar deleita, con el tiempo esta acción acaba estresando, ya que tarde o temprano, el adicto o adicta al juego dejará de sentirse bien con el juego. Se entiende mejor, si tenemos en cuenta sus testimonios: es vivir instalados en la continua mentira, perder mucho dinero, no saber cómo hacer frente a las deudas, vivir aislados de todos, centrados únicamente en el juego y saberse unos miserables sin atisbos de cambio; todo ello tiende a crearles unos niveles de malestar muy altos, donde es fácil que la ansiedad, el estrés, la irritabilidad, la depresión, la desesperación, así como la idea del suicidio, afloren de forma continuada.

Yo tuve que ir al médico ya desquiciao. Fui al médico de cabecera y me dio la baja; yo supongo que cuando el médico me vio, no se lo pensó, y me la dio porque estaba desquiciado (Jugador, 55 años).

Estas tan metida en el juego que vives para él. Llegas a un estado tal de estrés y ansiedad que piensas que el pecho te va a estallar de la presión que sientes (Jugadora, 66 años).

Conexo a esta realidad de malestar, hemos visto que en algunas historias de juego renacen situaciones adictivas, inicialmente superadas y, en otras, el consumo de drogas deviene con la conducta de juego, creándose en todas ellas auténticas situaciones poliadictivas. Cómo hemos podido ver, el consumo de alcohol, tabaco y cocaína suele ser una constante en la vida del adicto al juego, sobre todo esta última en los jugadores que no sobrepasan los cuarenta años. Reconocen que acceder a las drogas es fácil, ya que su conducta de juego se desarrolla en loca-

${ }^{1}$ Tan sólo se ha podido obtener el relato de cuatro mujeres jugadoras. Situación que visualiza el principal punto débil de este estudio, confirmando una vez más la realidad observada, cuando alude al tema de que son muy pocas las jugadoras que deciden asistir a centros de tratamiento para salir de la adicción. 
les donde se venden estas sustancias, facilitándoles el consumo. De igual modo asumen que su consumo les incita a jugar, sin tener que pensar en el tiempo ni en el dinero ni en las consecuencias negativas que tiene en sus vidas. Beber alcohol o esnifar cocaína supone, para algunos, alcanzar un nivel de euforia o excitación capaz de hacerles aumentar su emoción por el juego.

Yo estuve en la droga también, estuve enganchao en la droga. Empecé a consumir alcohol y muchos fines de semana cocaína y cuando consumía cocaína y el alcohol es que me volvía loco, me iba detrás de la máquina y estuve así un montón de tiempo (Jugador, 35 años).

Otros, sin embargo, lo hacen con el ánimo de mitigar o eliminar la sensación de culpabilidad, sobre todo cuando pierden; o simplemente beben para sentirse más relajados, llegando a experimentar un estado de bienestar no logrado hasta esos momentos.

Yo bebía de cualquier forma. Ese era el problema. Me bebía unas copitas jugando, pero bebía más cuando perdía. Ya borracho no pensaba en na (Jugador, 47 años).

Beber me ayudaba a relajar un poco la tensión que tenía. El problema era cuando lo mezclaba con la coca, y es que me volvía loco y gastaba (...) (Jugador, 35 años).

Otra de las repercusiones personales de gran calado es el desgaste psicológico que suele acarrearles muchos problemas de ansiedad y depresión, derivados fundamentalmente de la doble vida que llevan normalmente. Testimonian que los elementos de mayor estrés están relacionados con la falta de control en el juego, la necesidad constante de dinero y el pensar qué hacer para encontrarlo.

Psicológicamente acabas derrotao. El juego, psicológicamente, es peor que la droga. Sobre todo me ha afectado mucho la presión porque nadie se enterara de lo que hacía. Piensas en que si tu mujer se entera de todo va a echarte de casa y te quedas tirao en la calle y ¿dónde vas? (Jugador, 35 años).

Lo peor de todo es esconderte, permanecer callao para que no te descubran y poder seguir jugando. Hasta que no estas muy metido (...) que ya te da igual too, en lo único que piensas es que tu familia no te descubra y te estropee la fiesta (Jugador, 53 años).

\subsection{Derivaciones económicas y laborales}

Tanto los jugadores como los familiares coinciden en establecer que el ámbito que se va a ver más vapuleado por la adicción es el monetario. La factura económica que tiene es casi imposible de cuantificar, según relatan nuestros entrevistados y entrevistadas. Esto se explica a partir de que la acción de gastar dinero hay que entenderla desde diferentes marcos de significación. En primer lugar, el adicto hipoteca su presente económico en aras de su juego, teniendo que vivir situaciones de necesidad extrema o en la tesitura de que o bien otros le tengan que satisfacer sus necesidades más básicas, o sea él quien tenga que ponerse a trabajar para poder subsistir.

Yo te puedo decir que no había dinero ni para comer. Tuve que recurrir a mis padres, a mis suegros y a una hermana mía que todos los meses metía dinero en mi casa para que mis hijos y mi mujer pudiesen comer algo (Jugador, 55 años).

Me tuve que poner a trabajar y uno de mis hijos que estaba en la mili me mandaba todos los meses cuando cobraba algo de dinero (Familiar, 59 años).

Además de sufrir un presente mísero, el ludópata tiene que vivir con la realidad de haber hipotecado también su futuro, al tener que hacer frente a todas las deudas acumuladas, que en muchos casos suponen una cantidad ingente de dinero.

Yo recuerdo que llegó un momento en que era tan grande el agujero que estaba desesperao. Cuando llegué a la asociación debía alrededor de 14 millones de pesetas que todavía los estoy pagando (Jugador, 55 años).

Pero esto no se queda sólo aquí; también habría que aplicar el modelo de análisis coste-beneficio que la adicción introduce con respecto al tema económico. Todos los entrevistados y entrevistadas son conscientes de las oportunidades perdidas, en tanto que han dejado de percibir y de disfrutar de una serie de ventajas económicas, de no haberse instalado en sus vidas la adicción.

Lo que peor llevas es darte cuenta de todo lo que has perdido. Yo pienso en todo lo que me he gastado en el juego y pienso en lo que podría tener ahora si no lo hubiese tirado con el juego (Jugador, 45 años).

Teníamos una boutique de pan que nos reportaba todos los meses un buen dinero. Con el tiempo y con el problema resuelto mi marido y yo he- 
mos hablado de todo esto, de lo que podíamos tener y de lo bien que podíamos haber vivido con el negocio que teníamos (Familiar, 53 años).

Con respecto al tema laboral, diremos que todos coinciden en apuntar que, en los comienzos de su adicción, tiende a afectarles sobre todo a las condiciones relacionadas con cómo van a ser capaces de desarrollar su trabajo. Faltar al trabajo, solicitar bajas continuas o simplemente no acudir a él, suelen ser las opciones que dicen haber elegido para solventar su situación laboral.

En la fábrica ya no me tenían ningún respeto pues yo fallaba más que una escopeta caña. ¡Yo no sé como aguantaron tanto! Yo siempre tenía excusas para quitarme del medio (Jugador, 55 años).

Te inventas cualquier cosa para no ir a trabajar. Vives en una continua mentira. Yo mentía para todo, para no ir a trabajar (...) (Jugador, 44 años).

De igual modo reconocen haber sufrido muchos problemas de concentración laboral, dado que la mayoría de ellos sólo piensan en jugar, perdiendo con ello el interés por todo y por todos; la única fuente de vida emana de la propia necesidad de jugar.

Yo, de lo único que me preocupaba era de jugar. Estaba trabajando y sólo me acordaba de la máquina. Siempre el juego (Jugador, 53 años).

Te olvidas de todo. No puedes concentrarte en el trabajo, cuando estas tan metida en el juego no puedes pensar en el trabajo. Realmente es así, el juego puede más que tú (Jugadora, 58 años).

También reconocen que, conforme su situación de juego se va deteriorando, lo va haciendo también su situación laboral. El descenso considerable de su productividad laboral suele ser el primer síntoma en aparecer. No obstante esto no suele quedar aquí. En algunos casos vemos como la situación se hace tan insostenible que acaban perdiendo el trabajo por un incumplimiento manifiesto de sus responsabilidades laborales.

Yo estuve al borde de perder mi dignidad profesional y personal, pero nada yo seguí igual. Yo ya el trabajo lo tenía prácticamente abandonao (Jugador, 66 años).

Por culpa del juego perdí varios trabajos. Como uno no es consciente de lo que tiene entre manos, no piensa en las consecuencias (Jugador, 53 años).
En otros casos, esa pérdida viene acompañada de conductas ilegales dentro del propio entorno laboral. Cuando el jugador agota todas las fuentes de financiación, legales y posibles, y necesita seguir jugando, suele emprender su periplo de búsqueda de dinero en su trabajo. Se empieza por robar a los compañeros de trabajo y se termina metiendo la mano en la caja del dinero, cuando se cuenta con esa facilidad.

Gastaba dinero de los clientes y llego el día en que se descubrió. Debía dinero a la empresa, a los clientes, incluso llegué a falsificar la firma de mi mujer para pedir un préstamo (Jugador, 47 años).

Empecé a trabajar en una empresa de seguridad y pronto me ofrecieron un puesto en la Delegación de Huelva y vi las puertas abiertas y ahí comenzó de nuevo mi calvario. Mientras iba a ver a mis trabajadores, miraba las obras cercanas y el material que se podía vender y había días que vendía en puertas, azulejos, ventanas, etc. (Jugador, 38 años).

Como resultante de esta situación, el jugador o jugadora pueden verse en dos escenarios diferentes: o bien ser despedidos de manera fulminante o bien ser degradados laboralmente. Esto último suele acontecer cuando se conoce su adición y se toma como una «eximente del delito», ofreciendo al jugador la posibilidad de corregir la situación devolviendo lo robado y pidiendo ayuda.

Me hizo falta dinero y terminé robándoselo a la señora que cuidaba. Falsifiqué su firma y me fui al banco, saqué el dinero y yo encantá. La hija me despidió y me denunció (Jugadora, 39 años).

Cuando se supo en mi empresa lo del dinero yo no podía ir a ningún sitio, ni de permiso. Mi jefe me preguntó ¿qué es lo que pasa? Y yo le dije mire usted pasa esto y me dijo él: muy bien ¿te comprometes tú a pagar el dinero?; yo le dije que sí, y eso se calló totalmente (...) el que más mandaba tomó conciencia de que esto era una enfermedad y lo que hizo fue cambiarme de un sitio a otro. Me quitaron de la oficina y me pusieron en otro sitio (Jugador, 60 años).

Además no podemos olvidar el dato, anteriormente reseñado, de que una parte de los jugadores y jugadoras, sobre todo los primeros, cargan con otras adicciones a sus espaldas que, unidas a la del juego, no hacen más que amplificar su problema a todos los niveles. 
Es imposible trabajar en condiciones cuando no has pegao ojo en toda la noche harto de copas y de otras cosas (Jugador, 35 años).

Muchas veces iba al trabajo en muy malas condiciones. Sin dormir, sin comer, con varias copa y sin asearme. La verdad es que muchas veces me iba del bar a trabajar (Jugador, 45 años).

\subsection{Derivaciones legales 3 sociales}

Cómo acabamos de ver, una parte de los adictos al juego se ven inmersos en problemas legales, causados por los excesos económicos a los que tiene que hacer frente, al no ser capaces de contener su conducta de juego. Robar, hurtar, falsificar cheques, emitir cheques sin fondos, falsificar firmas, etc., suelen ser los delitos que tienden a cometer. Como resultado de estas conductas ilegales, al jugador o la jugadora puede abrírsele un proceso judicial y acabar con una sentencia de cárcel, como le ha ocurrido a una de nuestras jugadoras.

No tenía nada de dinero ni para comprar el pan. Cogí y falsifiqué una firma y me fui al banco y saqué dinero. Me fui a jugar y al otro día volvía a sacar dinero, novecientos euros en total y me llamó la hija, me dijo lo que había pasado y me denunció y estuve a punto de ir a la cárcel. Dos años y siete meses me echaron por novecientos euros (Jugadora, 39 años).

Sabedores de que esta situación incrementa o añade mayores niveles de estigmatización social a sus vida, tienden a procurar que esta información se haga lo menos pública posible. De ahí que se las ingenien para que no llegue a oídos de su contexto familiar más próximo (hijos), dadas las consecuencias que esto puede tener, no sólo a nivel personal, sino también en lo social.

Mis hijos no saben nada de lo de la cárcel. Saben que estoy aquí, que yo iba al bingo, pero lo de la cárcel no. Estas cosas cuanta menos gente lo sepa mejor, porque después la gente te mira mal, miran mal a tus hijos y pueden tener problemas en el colegio, con sus amigos y yo no quiero que pase nada de esto (Jugadora, 39 años).

Cómo hemos podido comprobar, a lo largo de los diferentes testimonios dados por nuestros sujetos de estudio, con el tiempo la adición al juego termina por desencadenar un gran aislamiento social del jugador. Entre las causas nombran a la propia dinámica del juego que les hace jugar en soledad, tanto por deseo propio de no ser molestados mientras juegan o porque, abstra- ídos por él, acaban desatendiendo cualquier otra faceta de su vida.

Yo al principio empecé jugando con mis amigos pero al final terminé jugando solo (Jugador, 29 años).

Me pasaba la mayor parte del día metido en el salón de juegos, me olvidaba de todo, de amigos, de familia, de todo, hasta de recoger a mis hijos del colegio (Jugador, 38 años).

De igual modo reconocen que su tendencia a sustraer o no devolver el dinero prestado acaba pasándoles factura, en cuanto que la situación les hace ser esquivos y rechazados por las personas que tienen a su alrededor.

Es tanto el dinero que debes que acabas huyendo de todos. Yo tenía broncas con mis hermanos y con algunos amigos que me habían dejao dinero y querían que se lo devolviese y yo claro no podía. Lo peor es que como al final sabes que tu familia no te lo va a volver a prestar si se lo pides, acabas robándoselo (Jugador, 47 años).

Pero este problema no sólo se posiciona del lado del jugador, sino que la familia también va a verse afectada. Tanto, unos como otros, manifiestan que la familia tarde o temprano termina pagando las iniquidades del juego. Las deudas que adquiere el jugador pasan a ser deudas de la familia por lo que ésta va a verse acorralada por los acreedores sintiendo una gran vergüenza ante la situación, que hará que poco a poco acabe retirándose del ámbito social recluyéndose en casa.

Yo pasé mucha vergüenza y miedo. Cuando yo me enteré de todo lo que debía y que había acudido a prestamistas. Entonces él cobraba y tal como cobraba ya estaba uno o dos esperándole en la puerta y venga a pagar (Familiar, 53 años).

Enterarte de que tu marido roba para jugar es algo muy tremendo. Me afectó mucho porque la verdad sientes tal vergüenza que no sabes que hacer (Familiar, 59 años).

Por último, y como consecuencia de sus deudas, algunos de ellos han tenido graves problemas con el banco, ya que al no pagar, terminan por embargarles la vivienda. Otros terminan desalojados, si viven de alquiler, y esto en contextos reducidos, como puede ser un barrio o un pueblo, facilita que los vecinos se puedan enterar de su situación, incrementándose con ello su sensación de desprestigio social. 
Entramos en un proceso de embargo del piso por la Caja porque dejé de pagar algunas letras. Pero al final lo pudimos solucionar cuando vine a la asociación (Jugador, 55 años).

Enseguida de casada empecé a sufrir las consecuencias de la adicción al juego y al alcohol de mi marido. En ese tiempo tuvimos dos desahucios de dos casas y ya en la última tuve que buscar sola donde irnos a vivir, ya que él ante estos problemas se quitaba del medio. La verdad es que me he visto en situaciones muy difíciles y he pasado mucha vergüenza por su problema (Familiar, 44 años).

\section{Discusión y conclusiones}

Si tenemos en cuenta lo narrado por nuestros sujetos de estudio, vemos que su discurso no se desvía ni un ápice de lo que a nivel teórico se viene razonando. Se sabe que la ludopatía se caracteriza no sólo por la pérdida de control ante el juego, sino también porque esta conducta es capaz de generar problemas serios que afectan a la totalidad de su vida. Recordemos, que este aspecto es recogido de nuevo en el DSM-V como uno de los criterios a tener en cuenta en el diagnóstico de esta problemática.

Aunque no son muchos los estudios cualitativos que hay sobre este tema ${ }^{2}$, todos coinciden en determinar que ser ludópata conlleva muchos problemas. De ahí, que sea fácil coincidir con la propuesta expresada por Alonso-Fernández (2003) cuando alude que a nivel humano el «precio a pagar» hay que situarlo en el propio dramatismo que encierran todas las historias personales y familiares de juego. Al igual que en otros estudios llevados a cabo, tanto en población joven (Zapata, Torres y Montoya, 2011), como en trabajadores y estudiantes universitarios (Ruiz, 2014), vemos que los adictos al juego son personas que pronto dejarán de sentirse bien (Salas, 2014). Perder dinero, no saber cómo hacer frente a las deudas, mentir a la familia, a los amigos, descuidar su trabajo y sus obligaciones cotidianas, suelen generarles un nivel de malestar muy alto, al que a veces hay que unir otras conductas adictivas (Estévez y Calvete, 2007). De igual modo, diferentes estudios evidencian que el consumo de drogas parece ser una constante en la vida del jugador patológico ${ }^{3}$ (Pedrero, 2010; Castaño et al., 2011; Zapata, Torres y Montoya, 2011; Ruiz, 2014). Su acceso es fácil ya que su conducta de juego se desarrolla en locales donde venden estas sustancias, lo que facilita el consumo. De hecho, Pedrero (2010), apunta que el bar tiende a ser el escenario habitual en el que se suelen dar este tipo de conductas, haciendo coincidir varios estímulos: el alcohol, la máquina y en algunos casos la cocaína. Se apunta que la excitación o la euforia que causa el alcohol estimula a las persona a jugar, sin tener que estar pendientes del tiempo y del dinero invertido, ni de las consecuencias que se derivan de su comportamiento. Tanto es así que, en algunos casos el sujeto tiende a desvalorizar el potencial adictivo que tienen la conducta de juego, no manifestando que tiene el problema cuando acude a un centro de tratamiento.

De igual modo se pone sobre la mesa el hecho de que jugar suele acarrear muchos problemas de ansiedad y depresión, en parte derivados de la doble vida a la que se ve sometido el ludópata. Situación que se ve agravada si tenemos en cuenta que en algunos casos (sobre todo en la mujer) estos elementos pueden ser considerados como facilitadotes iniciales de la adicción (González, Astudillo, Toro y Prado, 2014). La falta de control del juego y la necesidad constante de dinero y tener que buscarlo serían los aspectos que, a título de algunos expertos, generan mayor estrés entre los varones ludópatas sobre todo (Jiménez, García, Montero y Perea, 2011). Todo esto suele desembocar en una situación límite que hace que cuando llegan a la fase de desesperación se ven acorralados y vislumbran el suicidio como la única opción de resolver sus problemas, aunque finalmente sean pocos los que opten por ella. De hecho, cada vez son más los estudios que ponen en valor la asociación que suele darse entre ambas dimensiones: el riesgo de suicidio con el riesgo de ser adicto al juego (George y Murali, 2005; Zapata Torres y Montoya, 2011; Pérez, 2011)

No obstante, es en el contexto familiar donde van a ser más determinantes las consecuencias, sobre todo a nivel económico, como hemos po-

\footnotetext{
${ }^{2}$ Concretamente destacan los estudios llevados a cabo en Navarra, Zaragoza y Andalucía.

${ }^{3}$ Un estudio llevado a cabo en Madrid pone de manifiesto que, como trastorno primario, el juego patológico, se presentó en sujetos cuya droga principal era la heroína (15 por ciento), la cocaína (45 por ciento ), el alcohol (35 por ciento) y las benzodiazepinas (5 por ciento) (Pedrero, 2010, p. 15).
} 
dido comprobar a lo largo de nuestro estudio. Además de la ruina económica, la familia tiende a sufrir una devastación afectiva y personal, que muchas veces pasa desapercibida, dado que en algunas de ellas, tanto el origen como el factor mantenedor de la adicción hay que situarlo dentro de su propio ámbito. Diferentes estudios han demostrado que los antecedentes adictivos y los estilos disfuncionales de relación familiar pueden contribuir al desarrollo y manteniendo de este tipo de conducta adictiva (Garrido, Jaén y Domínguez, 2004; Blanco, 2014).

Aunque, de nuevo, son pocos los estudios publicados sobre las consecuencias sociales que acarrea la adicción al juego, vemos que en todos ellos tiende a confirmarse (al igual que en el nuestro) la idea de que, con el tiempo, ésta termina por desencadenar un gran aislamiento social del jugador (Barroso, 2003; Blanco, 2014). De igual modo, nuestro estudio explicita que el precio social no sólo se posiciona del lado del jugador, también se va a ver muy afectada la familia, al ser víctima directa de los comportamientos del ludópata, ya que sin quererlo termina pagando los desmanes del jugador (Chóliz, 2006). Las deudas con los familiares y amigos, son consideradas deudas de la familia, por lo que la mujer sufrirá el ostracismo y la ira de los acreedores, y ella sentirá vergüenza por la situación y poco a poco irá retirándose del ámbito social y terminará por recluirse en casa, sobre todo cuando el ludópata termina teniendo problemas legales y/o judiciales; ya que, como apunta Domínguez (2009), es frecuente que le acompañen otros problemas asociados a conductas delictivas.

Al igual que sucede con otras adicciones sociales, las consecuencias del juego adictivo acaban esquilmando el ámbito laboral (Cruzado Díaz, Matos Retamozo y Kendall Folmer, 2006). $\mathrm{Si}$, en sus comienzos la adición determina las condiciones en como la persona desarrolla su trabajo (baja implicación laboral, absentismo, relaciones laborales conflictivas, etc.), conforme se agrava su situación de juego, también lo hará su situación laboral.

Tanto nuestro estudio como el llevado a cabo por Fernández-Montalvo, Báez y Echeburúa (2000) sobre este tema (adicción a las máquinas tragaperras $)^{4}$, tienden a confirmar lo especificado hasta este momento. Centrándonos en algunos resultados de interés, vemos que el 65 por ciento de los ludópatas, que en el momento de hacer el estudio se encontraban en una situación de desempleo, lo estaban por motivos relacionados con la adicción. O bien, porque habían sido despedidos del trabajo por haber robado o estafado, o por haber tenido que cerrar su propio negocio $^{5}$. Coincidiendo con el criterio clínico de estos autores, la justificación habría que encontrarla en el hecho en que, cuando un adicto está inmerso en el juego pierde el control del tiempo y se siente incapaz de abandonarlo para ir al trabajo, en parte influidos por las constantes distorsiones cognitivas que controlan su mente.

Independientemente de la variable que media en el sumario de despido ${ }^{6}$, lo que queda claro es que en la mayor parte de estos procesos se consideran como despidos procedentes, sin que se tenga en cuenta el diagnóstico de juego patológico. En cualquier caso, esta consideración diagnóstica sólo se tiene en cuenta, de manera excepcional (y así lo hemos advertido en nuestro trabajo), como una circunstancia eximente en procesos de responsabilidad penal, siempre y cuando el ludópata demuestre que está inmerso en un proceso de rehabilitación.

De todo lo escrito es fácil concluir manifestando que la adicción al juego debe ser comprendida como un gran problema social, ya que si realizamos una valoración holística de todos sus consecuentes, no nos queda otra disyuntiva que poner en valor las palabras escritas por Becoña Iglesias (1996) cuando expresa que:

Todo el sistema social tiene que pagar un alto precio. Se calcula que por cada ludópata que exis-

${ }^{4}$ El 72,7 por ciento de la muestra presentó algún problema laboral. El estudio contó con una muestra final de 121 pacientes que acudían en busca de tratamiento al Centro de Salud Mental de Rentaría (Guipúzcoa) y a la Asociación de Ayuda a Ludópatas Ekintza-Dasalud (Rentaría, Guipúzcoa) entre los años 1993 y 1997.

5 De manera general, las anotaciones que hacen sobre las consecuencias laborales, tienen su base en impresiones clínicas y en paralelismos con lo que ocurre en otras conductas adictivas, fundamentalmente el alcoholismo.

6 Entre las principales consecuencias del hecho este estudio revela que el 47,1 por ciento fue despedido por ser absentista laboral, el 39,6 por ciento por tener problemas de concentración y disminución del rendimiento y el 28 por ciento por haber robado o estafado en su ámbito laboral. 
te se ven afectadas otras 10 ó 20 personas entre familiares, amigos y compañeros de trabajo. De ahí, que cuando se habla de ludopatía, no sólo hay que considerar al enfermo, sino también a las personas que directa o indirectamente están vinculadas a ese problema (p. 136).

\section{Referencias bibliográficas}

Alonso-Fernández, F. (2003). Las nuevas adicciones. Madrid: TEA Ediciones.

APA. (2013). Diagnostic and Statistical Manual of Mental Disorders (DSM-V) (Fifth Edition). Washington, DC: American Psychiatric Association.

Barroso Benítez, C. (2003). Las Bases Sociales de la Ludopatía. Tesis Doctoral Universidad de Granada, Granada, España.

Becker, S. (1974). Historias de vida en Sociología. En: J. Balán, Las historias de vida en las ciencias sociales. Teoría y técnica. Buenos Aires: Ediciones Nueva Visión.

Becoña Iglesias, E. (1996). La ludopatía. Madrid: Aguilar.

Blanco, P. (2014). El Estudio de las Adicciones Sociales. EL juego como Adicción Social: Problemática social, Contexto Familiar y Movimiento Asociativo. El caso de Huelva. Tesis doctoral inédita Universidad de Huelva. Huelva. España.

Castaño, S. et al. (2011). Estudio epidemiológico sobe juegos de azar y factores asociados en población universitaria de la Universidad de Manizales, Colombia 2010. Archivos de Medicina, 11(2), 101-113.

Castilla, C., Berdullas, S., Vicente, A. y Villamaría, S. (2013). Apuestas Online: el nuevo desafío del juego patológico. Enfocop. Boletín General de la Psicología en España, 61, 4-6.

Chóliz, M. (2006). Adicción al juego de azar. Recuperado de: htpp://www.uv.es/choliz. (Consultado el 08/06/2015).

Cruzado Díaz L., Matos Retamozo L. y Kendall Folmer R. (2006). Adicción a internet: Perfil clínico y epidemiológico de pacientes hospitalizados en un instituto nacional de salud mental. Rev Med Hered, 17(4), 196-205.

Domínguez, A. (2009). Epidemiología y factores implicados en el juego patológico. Apuntes de Psicología, 27(1), 3-20.

Fernández-Montalvo, J., Báez, C. y Echeburúa, E. (2000). Ludopatía y trabajo: análisis de las repercusiones laborales de los jugadores patológicos de máquinas tragaperras. Clínica y Salud, 11(1), 5-14.

Ferrarotti, F. (2006). Historias de vida y ciencias sociales. Perifèria. Revista de recerca i formació en antropología, 5, 1-14. URL: www.periféria.name.

Garrido, M., Jaén, P. y Domínguez, A. (2004). Ludopatía y relaciones familiares. Barcelona: Paidós.

George, S. y Murali, V. (2005). Pathological gambling: and overview of assessment and treatment. Advances Psychiatric Treatment, 11, 450-456.

González, P. C. Astudillo, E. Y., Toro, K. G. y Prado, A. (2014). Prevalencia de la adicción al juego y estrategias de afrontamiento adolescentes escolarizados en el municipio de la Unión (Colombia). Revisa Cultura del Cuidado, 11(1), 39-49.

Jiménez, A., García, C., Montero, M. y Perea, M.C. (2011). Estudiantes universitarios y juego patológico. Un estudio empírico de la Universidad de Murcia. Escritos de Psicología, 4(3), 50-59.

King, D., Delfabbro, P. y Griffiths, M. (2010). The convergence of gambling and digital media: implications for gambling in Young people. Journal of Gambling Studies, 26(2), 175-187.

Olason, D.T., Krisjansdottir, E., Einarsdottir, H., Haraldsson, H., Bjarnason, G., \& Derevensky, J. (2011). Internet Gambling and problem gambling among 13 to 18 year old adolescents in Iceland. Journal Mental Health Adiction, 9(3), 257-263.

Pedrero Pérez, E. J. (2010). Detección de adicciones comportamentales en adictos a sustancias en tratamiento. Trastornos Adictivos, 12(1), 13-18.

Pérez del Río, F. (2011). Las adiciones sin sustancia en estos últimos 40 años. Norte de Salud Mental, IX(40), 47-56.

Rojo, A. (1997). Los documentos personales en la investigación sociológica: Historias de Vida, Relatos, Biografías y Autobiografías. Su diferenciación y pertinencia. Revista General de Informa- 
ción y Documentación, Servicio de Publicaciones de la Universidad Complutense de Madrid, 7(2), 385-395.

Ruiz Pérez, J.I. (2014). Juego patológico y dependencia al alcohol en una muestra de trabajadores y estudiantes universitarios: Prevalencias, interrelaciones y diferencias de género. PSYCHOL. AV. DISCIP, 8(1), 33-42.

Salas Blas, E. (2014). Adicciones Psicológicas y los nuevos problemas de salud. Cultura: Lima (Perú), 28, 111-146.

Sarabia, I., Estévez, A. y Herrero, D. (2014). Situación del juego con dinero en jóvenes y adolescentes. Revista Española de Drogodependencias, 39(3), 57-68.

Secades Villa, R. y Villa Canal, A. (1998). El Juego Patológico. Prevención, Evaluación y Tratamiento en la Adolescencia. Madrid: Pirámide.

Volberg, R.A., Gupta, R., Griffiths, M.D., Olason, D. y Delfabbro, P. (2011). An international perspective on youth gambling prevalence studes. International Journal of Adolescent Medicine and Health, 22(1), 3-38.

Zapata, M.A., Torres, Y. y Montoya, L.P. (2011). Riesgos de Juego Patológico. Factores y Trastornos mentales asociados en jóvenes de Medellín - Colombia. ADICCIONES, 23(1), 17-25. 